\title{
Erodibility of soil above the groundwater level: some test results
}

\author{
Anna Shidlovskaya ${ }^{1, a}$, Jean-Louis Briaud ${ }^{2}$, Mabel Chedid ${ }^{2}$ Keshavarz M. $^{2}$ \\ ${ }^{1}$ National Mineral Resources University (University of Mines), St. Petersburg, Russia (shidanna2013@gmail.com) \\ ${ }^{2}$ Texas A\&M University, College Station, TX, USA
}

\begin{abstract}
The paper presents a study on erodibility of soil above the groundwater level where the water is in tension. Such soils particularly clays are very sensitive to moisture and temperature changes and can be eroded significantly by water flow. The erosion of clay and sand samples from the US National Geotechnical Experimentation Site at Texas A\&M University is studied. Two sets of experiments are done with the clay and the sand. The first set was performed on sample collected in November 2014 and the second set on samples from June 2014. The depth of the samples varied from 0.6 to $3.6 \mathrm{~m}$ where water content and density changes. A series of erosion tests was performed in the Erosion Function apparatus (EFA) with the intact clay and then with the sand reconstructed to the field density and field water content. The erosion tests are performed at different flow velocities varying from $0.5 \mathrm{~m} / \mathrm{s}$ to $5.5 \mathrm{~m} / \mathrm{s}$. The erodibility is quantified by the relationship between the erosion rate and the water velocity called the erosion function. Some relationships between the critical velocity and common soil properties are discussed. The collapse of the clay structure when inundated (soaking) is studied.
\end{abstract}

\section{Introduction}

Erosion of soil is a phenomenon which affects many engineering infrastructure elements. Some examples include bridge failures by scour during storms, levee failures by overtopping during hurricanes or floods, internal erosion of dams, suffusion in a soil in the foundation, meander migration in rivers, river banks erosion and slope failure associated with that, cliff and shore erosion, and surface erosion of highway embankments. This paper addresses the erosion of soils at shallow depth above the water table where the water is in tension. Erosion laboratory tests are presented as well as geotechnical properties with the goal of gaining some insight on the relationship between erodibility and soil properties.

\section{Definition of erodibility}

Erosion is the removal of soil particles by flowing water causes soil structure collapse. The water applies the load on the soil which provides a level of resistance to the erosion process. The water also affects soil not only mechanically but also chemically. The chemical processes between water and soil are leaching and dissolution of soil that depends on the type of structure and bonding as well as salt composition of soil. Erodibility is the potential for erosion and can be

quantified by the relationship between the erosion rate $z$ $(\mathrm{mm} / \mathrm{hr})$ and the water velocity $\mathrm{v}(\mathrm{m} / \mathrm{s})$; therefore erodibility is not a single number like the friction angle of a soil for example but a curve like a stress strain curve. In

fact the $\dot{z}$ vs. v curve is called the erosion function and plays the role of constitutive law for erosion processes. One problem is that the velocity varies in the water body and is theoretically zero at the interface between the water and the soil where the erosion takes place. So the water velocity, while a simple and convenient parameter, is not an ideal parameter for the erosion function. Instead many researchers have been using the shear stress $\tau$ imparted by the water at the interface. This shear stress is extremely small but so is the soil resistance in many instances. This is why erosion can be devastating in many cases. In this paper, the erodibility of a soil will be characterized by the erosion function expressed as the erosion rate $z$ vs. water velocity v. This erosion function is often described by using the following model:

$$
\dot{z}=\alpha_{v}\left(v-v_{c}\right)^{\beta_{v}}
$$

Where $\dot{z}$ is the erosion rate in $\mathrm{mm} / \mathrm{hr}, \alpha_{v}$ is soil constant corresponding to the erosion rate when $v-v_{c}$ is equal to $1 \mathrm{~m} / \mathrm{s}, \mathrm{v}$ is the mean depth flow velocity, $\mathrm{v}_{\mathrm{c}}$ the critical velocity, $\beta_{v}$ the slope of the velocity based erosion function in $\log \log$ space.

a shidanna2013@gmail.com 


\section{Erosion function apparatus or EFA}

The Erosion Function Apparatus test or EFA test was developed in the early 1990s to measure the erodibility of soils and soft rocks. The principle is to go to the site where erosion is being investigated, collect samples within the depth of concern, bring them back to the laboratory and test them in the EFA. The $75 \mathrm{~mm}$ outside diameter sampling tube is placed through the bottom of the conduit where water flows at a constant velocity. The soil or rock is pushed by a piston out of the sampling tube only as fast as it is eroded by the water flowing over it. The test result consists of the erosion rate $\dot{z}$ versus shear stress $\tau$ curve and erosion rate $\dot{z}$ versus mean flow velocity $\mathrm{v}$ curve. This paper presents only the results of the erosion in terms of the erosion rate versus water flow velocity.

For each flow velocity v, the erosion rate $\dot{z}$ (mm/hr) is simply obtained by dividing the length $\mathrm{h}$ of sample eroded by the time $t$ required to do so.

$$
\dot{z}=\frac{h}{t}
$$

The velocity $\mathrm{v}$ is obtained by measuring the flow $\mathrm{Q}$ and dividing by the flow area A.

\section{Erodibility parameters}

In order to characterize the erodibility of a soil with a single number, it becomes necessary to isolate one of the elements of the erosion function or to associate certain ranges of erosion functions with a classification number.

Note that the erosion function is often plotted on a log log space to capture the extreme values with precision; this technique also has the advantage that the erosion function is often close to a straight line on this set of axes. Elements of the erosion function which are commonly used are the critical velocity $\mathrm{v}_{\mathrm{c}}$, the critical shear stress $\tau_{c}$, and the slope of the curve, $\beta_{v}$ and $\beta_{\tau}$. The critical velocity is the mean depth velocity of the water flow below which no erosion takes place. Practically, "no erosion" in the erosion soil test is defined as an arbitrarily low finite value of $0.1 \mathrm{~mm} / \mathrm{hr}$. The initial slope of the erosion curve defines how sensitive the soil erosion is to an increase in water velocity. It should be noted that even if water velocity tends to zero or water does not flow soil could soak in steady water that could be considered as a type of erosion.

\section{Erosion factors}

The erodibility of soils varies significantly from one soil to the next; therefore erodibility depends on the soil properties such as structure, lithology, grain size and chemical composition, type of bonding, physical and mechanical properties, and presence of fissures that has an effect on the full-scale field behavior of hard clay. It also depends on the properties of the water flowing over the soil. In this paper the full-scale behaviour of soil and the properties of the water are not considered as only samples are tested.

The soil above and below the groundwater level could erode in different ways depending on whether it is saturated or partially saturated with both air and water in the pores. The wet-dry cycles due to the weather and associated moisture migration in the soil profile transported by a thermal gradient during the year can also have an impact on the soil erodibility. For example, the formation of shrinkage cracks and then water flowing through the cracks can erode a soil significantly. In this case, erodibility will be affected by both the water velocity and the density of the shrinkage cracks pattern. This is particularly important at shallower depths with problems such as overtopping of levees during hurricanes or floods, river banks erosion, surface erosion of highway embankments and so on.

\section{Soil profile and properties}

The erodibility of soils above the groundwater level and clay in particular is very sensitive to moisture changes and water flow. For this research the soil was obtained from the National Geotechnical Experimentation Sites at Texas A\&M University. A total of 7 borings were drilled at the Clay site and at the Sand site. Three borings were conducted in November 2014 at both sites and four were conducted in June 2015 at both sites as well. The soil was sampled every $0.6 \mathrm{~m}$ in the interval of $0.6-3.6 \mathrm{~m}$ depth with $76 \mathrm{~mm}$ pushed thin wall steel tubes.

The ground elevation at the Clay Site is about 77 meters above MSL and the Sand site is about $79 \mathrm{~m}$ above MSL. The clay is terrace deposits of Pleistocene age. More precisely it is a calcium-carbonate-cemented lightbrown and reddish-brown clay containing nodules of calcareous and organic matter. The calcareous nodules and the calcium-carbonate-cemented clay mass show a strong reaction to acid. The amount of carbonates nodules in the clay decreases with depth from $25 \%$ of the sample volume at $0.6-1.8 \mathrm{~m}$ to $10-15 \%$ at $1.8-2.4 \mathrm{~m}$ and $5 \%$ at 2.4-3.6 $\mathrm{m}$. The clay appears multi-fissures at the depth from 0.6 to $3.6 \mathrm{~m}$. The major clay minerals for the clay are primarily smectite group (very likely montmorillonite) with some illite. The unit weight of solids varies from $24.7 \mathrm{kN} / \mathrm{m}^{3}$ at the $0.6-1.8 \mathrm{~m}$ to $25.9 \mathrm{kN} / \mathrm{m}^{3}$ at the $1.8-3.6 \mathrm{~m}$.

The sand at the Sand Site is from fluvial and overbank deposit of Pleistocene age. This sand is mottled light red silty sand slightly cemented by capillary water in tension. For testing, the sand samples from depths 0.6$3.6 \mathrm{~m}$ was remolded and reconstructed while matching the field density and the water content.

Figure 1 presents grain size distribution curves for the clay. The clay composed primary of clay-size and colloidal particles. The amount of clay particles varies from $62 \%$ to $82 \%$ through the clay profile. The sand consists of silt, sand and some gravel particles. The coefficient of uniformity varies from 3.1 to 4 . Figure 2 shows grain size distribution curves for the sand taken from the Clay Site in November 2015. The plasticity index of the clay varies from 22 to 36 . Table 1 shows the 
water content and total unit weight of the clay samples in November 2014 and June 2015. An expected fluctuation of water content and total unit weight between the winter (November) and the summer (June) is observed within the depth of 0.6-3.6 m (Fig. 3).

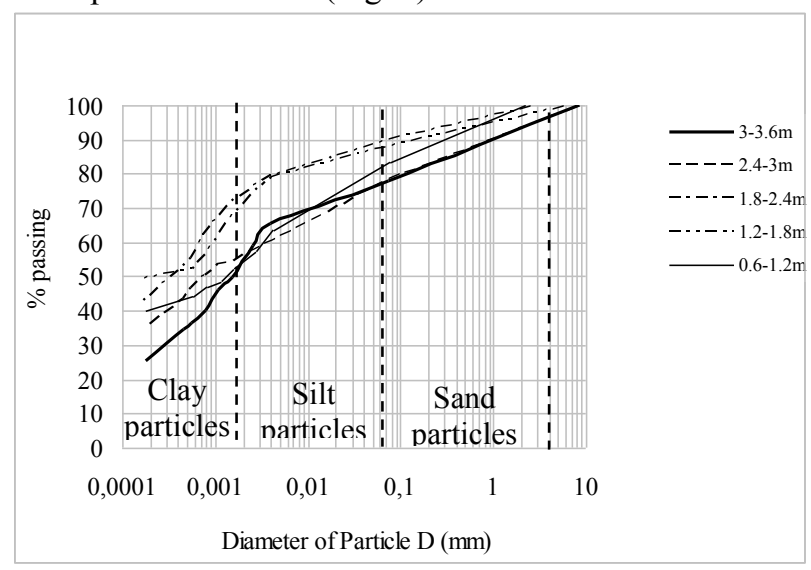

Figure 1. Grain size distribution of clay.

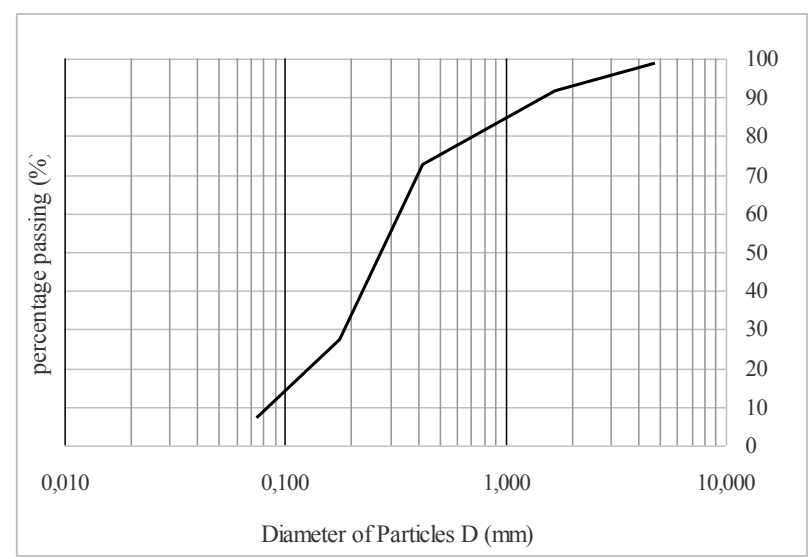

Figure 2. Grain size distribution of sand.

Table 1. Classification and properties of clay (National Geotechnical Experimentation Clay Site).

\begin{tabular}{|c|c|c|c|}
\hline $\begin{array}{c}\text { Soil } \\
\text { classification }\end{array}$ & Depth, m & $\begin{array}{c}\text { Water } \\
\text { content, \% }\end{array}$ & $\begin{array}{c}\text { Total unit } \\
\text { weight, } \\
\mathrm{kN} / \mathrm{m}^{3}\end{array}$ \\
\hline $\mathrm{CH} /$ fat clay & $0.6-1.2$ & $\frac{\mathrm{NA}^{*}}{20.5^{* *}}$ & $\frac{\mathrm{NA}^{*}}{19.7^{* *}}$ \\
\hline $\mathrm{CH} /$ fat clay & $1.2-1.8$ & $\frac{17.6^{*}}{21.8^{* *}}$ & $\frac{20.9^{*}}{21.4^{* *}}$ \\
\hline $\mathrm{CH} /$ fat clay & $1.8-2.4$ & $\frac{29.9^{*}}{22.8^{* *}}$ & $\frac{19.3^{*}}{20.8^{* *}}$ \\
\hline $\mathrm{CH} /$ fat clay & $2.4-3.0$ & $\frac{\mathrm{NA}^{*}}{22.5^{* *}}$ & $\frac{19.7^{*}}{20.1^{* *}}$ \\
\hline $\mathrm{CH} /$ fat clay & $3.0-3.6$ & $\frac{27.0^{*}}{22.7^{* *}}$ & $\frac{20.0^{*}}{\mathrm{NA}^{* *}}$ \\
\hline
\end{tabular}

* - water content and total unit weight of the samples obtained in November 2014; ** - water content and total unit weight of the samples obtained in June 2015.

Three zones in the clay profile from the top to the bottom can be identified based on the June results. The first zone is a zone of low water content $(0-1.2 \mathrm{~m})$; the second zone is a zone of increasing water content compared to the first zone $(1.2-1.8 \mathrm{~m})$; the third zone is a zone of higher and constant water content (1.8-3.6 m). Such variation may be due to the likely fluctuation of the groundwater level over the years. The GWL at the Clay Site is currently expected at a depth below 6 meters at the Sites

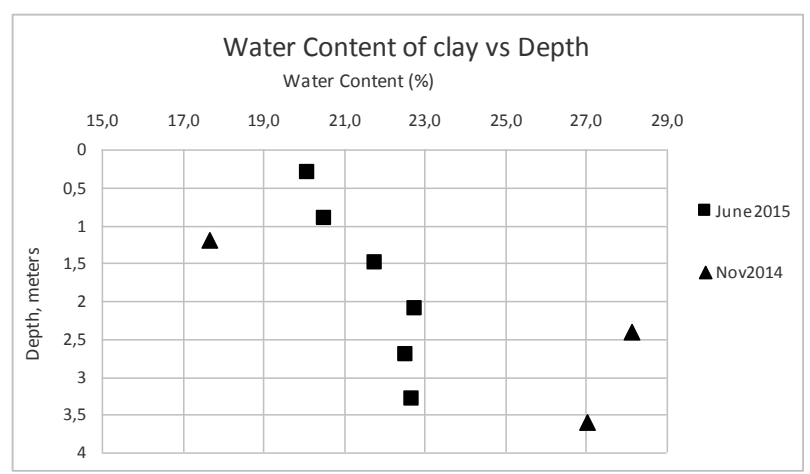

Figure 3. Water content of clay vs. depth

Groundwater is transported by thermal gradient which has an impact on the water content at shallow depth down to $3 \mathrm{~m}$. At a depth greater than $3 \mathrm{~m}$ at this location the soil temperature remains relatively constant throughout a year. However it is expected that the soil temperature could change below $3 \mathrm{~m}$ with an increase in a depth of shrink fissures. Measurements made in Houston indicate that the temperature variation between the ground surface and a depth of $3 \mathrm{~m}$ can reach 8 degree Celsius in the summer and 6 Celsius degrees in the winter. Within that zone, the thermal gradient can vary from 2 degree Celsius per meter in November to 2.6 degree Celsius per meter in June.

\section{Water soaking durability test results}

Water soaking of clayey soils is a phenomenon which affects the clay structure and causes its complete destruction in some cases. The reaction to soaking of clays varies from one soil to the next and depends mostly on the type of bonds between particles. These bonds include the increase in effective stress due to the tension in the water at the contact between particles. They are easily lost when the clay is immersed in water. Other bonds also play a role in this process. The clay tested is cemented with water-colloidal and crystallization bonding between particles. The first type of bonding is due to electromagnetic forces between water molecule and soil particles particularly colloids with a size of less than $0.0001 \mathrm{~mm}$. Because of this type of bonding, the strength of the dry clay decreases when getting wet. The second type of bonding between particles depends on the composition of the cementing material between particles. As was mentioned above, the clay is formed by calcium carbonates and likely gypsum bonding due to salt crystallization during drying periods. This type of bond is very likely destroyed by water especially if water contains aggressive $\mathrm{CO}_{2}$ and cannot be recovered even if the clay dries again. 
During the water soaking durability test, the clay samples were first air dried and then completely immersed in water; they all collapsed within 5 to 7 minutes after immersion. The effect of "melting sugar" and air bubbles formation was observed during the soaking of the clay.

\section{Erosion results in the EFA}

A series of erosion tests were performed in the Erosion Function apparatus (EFA) on the clay and sand samples collected in November 2014 and June 2015. The clay samples were undisturbed samples but the sand samples were reconstituted to match the estimated field density and measured water content. The erosion tests were performed at different flow velocities varying from 0.5 $\mathrm{m} / \mathrm{s}$ to $5.5 \mathrm{~m} / \mathrm{s}$. These tests were not repeatable because of the limit number of soil samples. The erodibility of the soil was quantified by the relationship between the erosion rate and the water velocity called the erosion function. Figs. 4 and 5 show the erosion functions of the clay and of the sand respectively. As seen in Fig. 4, all clay samples behaved mostly as medium erodibility soils with a general increase in erosion rate with an increase in velocity as expected. The erratic behavior of the sample from $0.6-1.2 \mathrm{~m}$ clay is due to a highly heterogeneous sample with different layers being eroded at different velocities.

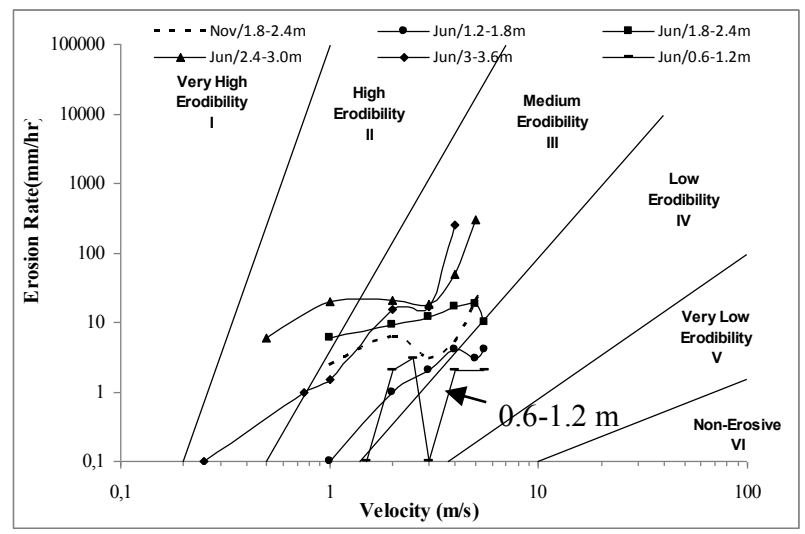

Figure 4. The erosion function of clay.

The relationship between the erosion rate and the water velocity of the sand is more consistent than the clay. The erosion rate increases with an increase in water velocity (Fig. 5). It was also observed that for the clay, the collapse of the clay structure when soaking in water correlated well with the erosion behavior of the clay. The clay samples were put in stationery water and left there for 24 hours. The clay structure for some samples depending on the soil water content and density collapsed even in 5-10 minutes after running the test. It was indicated that the more sensitive to water soaking the clay was, the more erodible it was in the EFA.

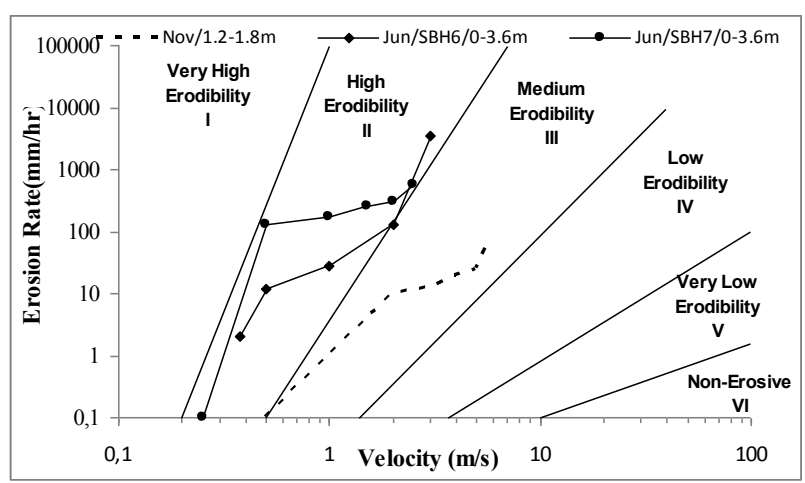

Figure 5. The erosion function of sand.

\section{Erosion and properties for Clay Site}

The relationship between the critical velocity and the soil properties is the only relationship investigated in this paper due to complexity of the relationship between erodibility and soil properties as well as the limited extent of the test results. The critical velocity is defined as the velocity corresponding to an arbitrary low erosion rate of $0.1 \mathrm{~mm} / \mathrm{hr}$.

A comparative analysis of the clay results at a depth of 1.8-2.4 $\mathrm{m}$ in November 2014 and June 2015 leads to the following observations (Fig. 6 and 7). The critical velocity for the clay with low water content $(22.8 \%)$ and higher dry density $\left(16.9 \mathrm{kN} / \mathrm{m}^{3}\right)$ in June is 3.3 times less than the critical velocity of the same clay in November with higher water content $(29.9 \%)$ and lower dry density $(14.8 \%)$. It is clear that this clay with lower water content and higher dry density is more sensitive to water flow and erodes more. The erosion function (Fig. 4) also indicates that the erosion rate of the clay at a depth of $1.8-2.4 \mathrm{~m}$ is higher in June than in November. The possible reason is that when the clay with the low water content and the higher water tension in the pores comes into contact with the water at the beginning of the erosion process, the water rushes into the pores. The air is compressed because it cannot escape and the particles are loosened and detached by this process. By comparison the clay with the higher water content has already come to water tension equilibrium and is less impacted by that phenomenon.

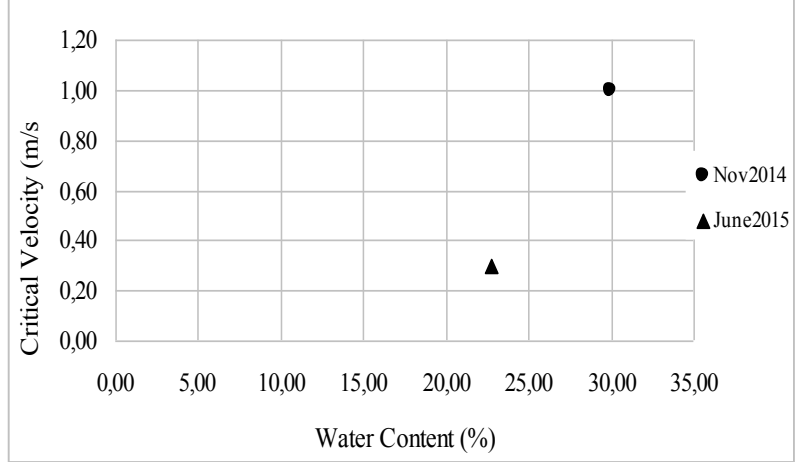

Figure 6. Critical velocity of 1.8-2.4 m depth clay vs. water content. 


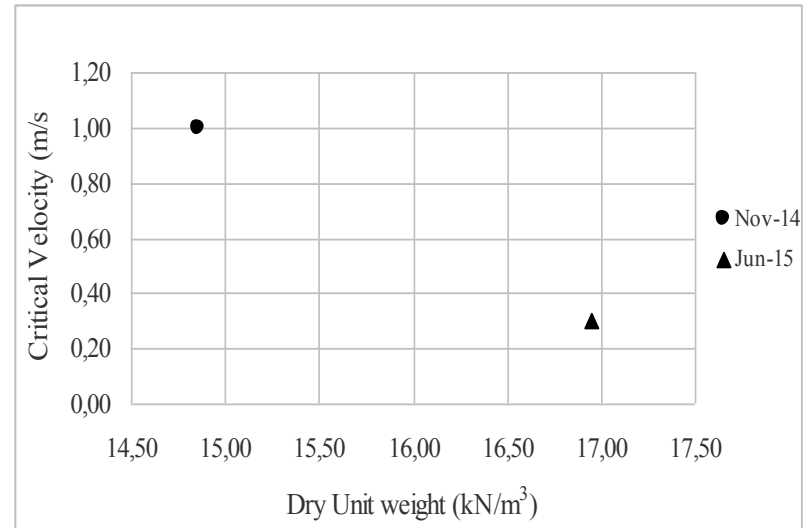

Figure 7. Critical velocity vs. dry unit weight of 1.8-2.4 m depth clay.

Other relationships between the critical velocity and clay properties were investigated without much success. The content of clay and silt particles did not show an identifiable relationship (Figs. 8 and 9).

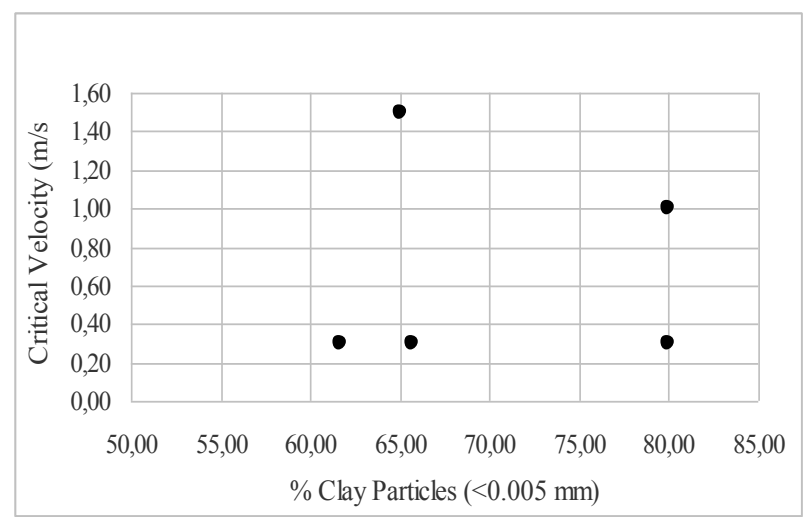

Figure 8. Critical velocity vs. percent of clay particles of clay.

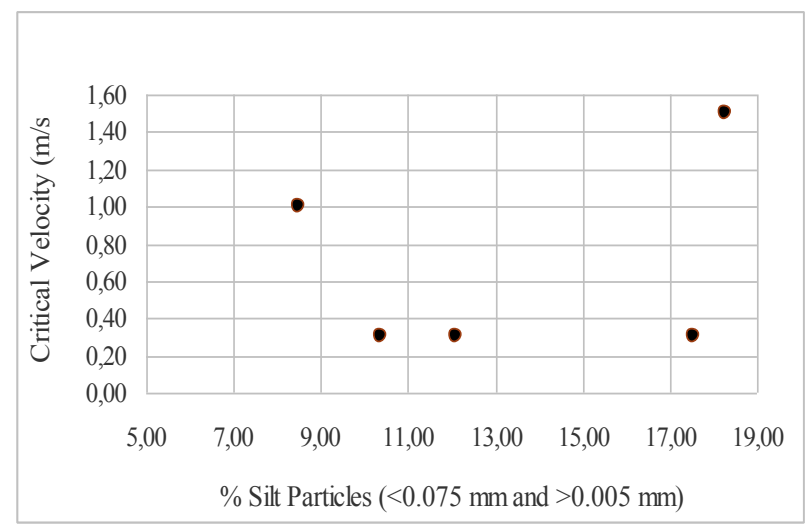

Figure 9. Critical velocity vs. percent of silt particles of clay.

It would seem reasonable to expect that the plasticity of clay would impact its erodibility with more erosion resistance for higher plasticity clays. This is mildly observed in Fig. 10 where there is a possible trend upward in the data between critical velocity and plasticity. This confirms that the mineral composition of clay is very important to understand its resistance to erosion.

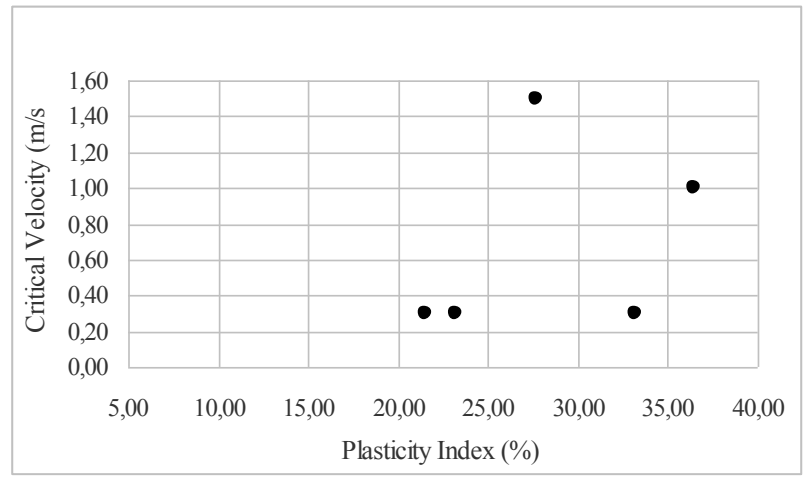

Figure 10. Critical velocity vs. plasticity index of clay.

The comparison on Fig. 11 between the critical velocity and the undrained shear strength does not show a strong correlation.

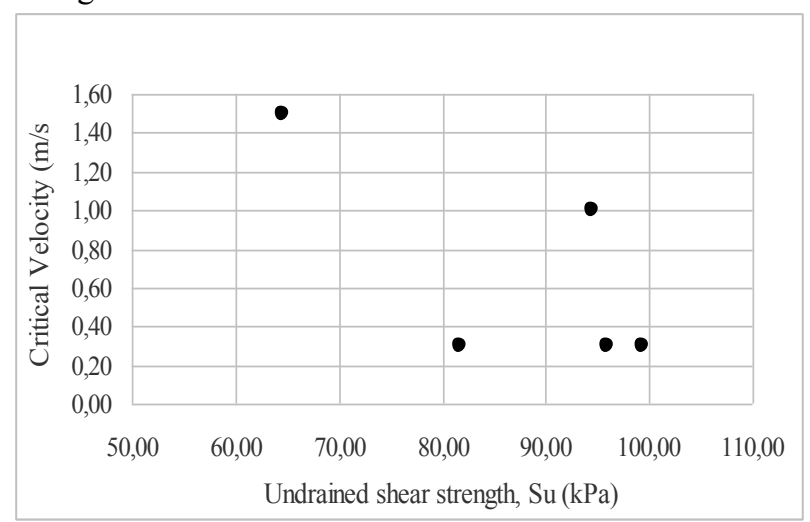

Figure 11. Critical velocity vs. undrained shear strength of clay.

\section{Erosion and properties for Sand Site}

The results of the tests performed with the sand samples confirm that the sand-water interaction is very different from the clay-water interaction. Figs. 12 and 13 show that the critical velocity of the sand decreases with an increase in water content and a decrease in dry density. This is contrary to the findings for the clay. The reason is that a denser particle arrangement helps resist the water flow better than a loose arrangement. In this sense compaction will help increase the critical velocity.

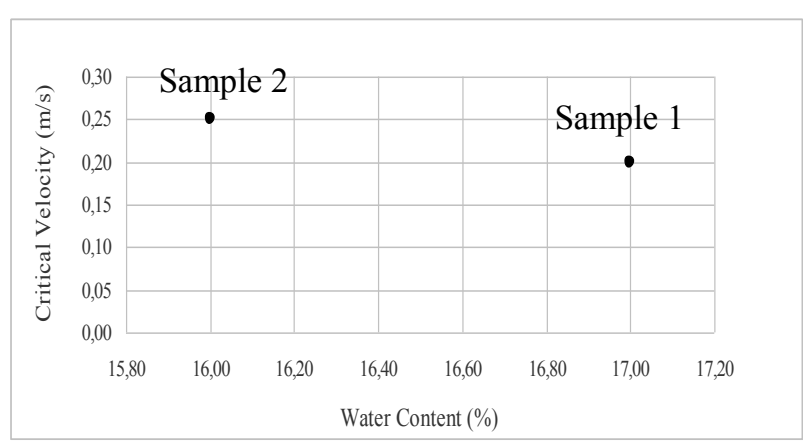

Figure 12. Critical velocity vs. water content of sand. 


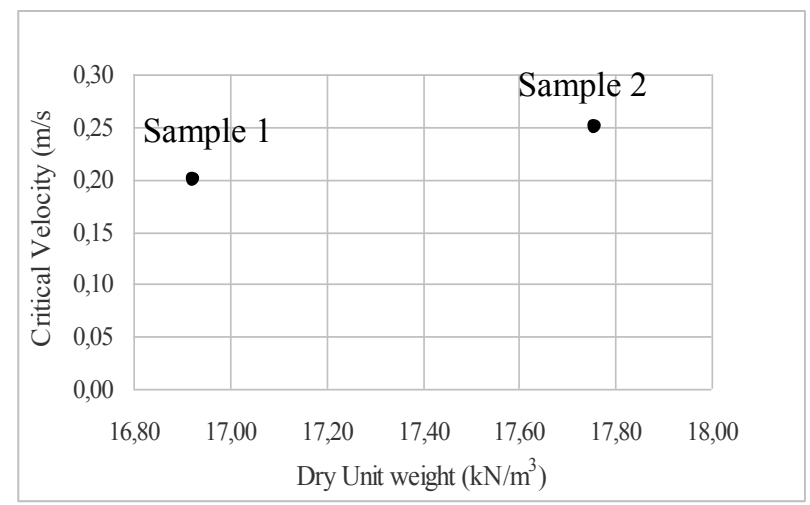

Figure 13. Critical velocity vs. dry unit weight of sand.

Fig. 14 shows that the critical velocity decreases as the sand becomes more uniform. Indeed the more uniform the sand is the higher the void ratio and the harder it is to reach a high level of compaction. Fig. 15 confirms that the critical velocity increases with an increase in the mean grain size D50 as is well known. Indeed sand behavior is controlled by the weight of the particles unlike clays. The heavier the particle is the more difficult it is to move it by water flow.

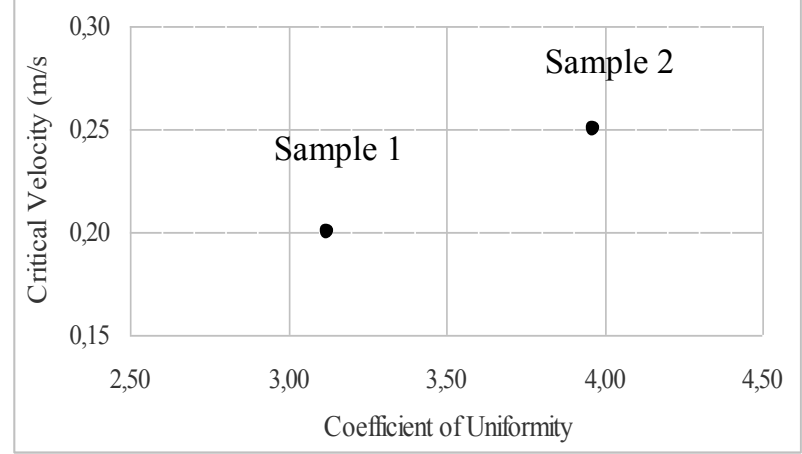

Figure 14. Critical velocity vs. coefficient of uniformity of sand.

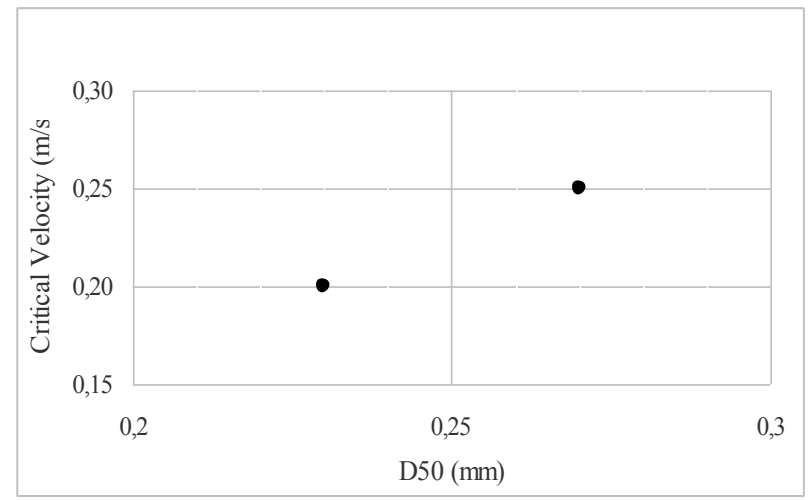

Figure 15. Critical velocity vs. D50 of sand.

\section{Conclusion}

This paper presents the results of a first set of experiments on the erosion characteristics of the soils obtained at shallow depths at the National Geotechnical Experimentation Site at Texas A\&M University. Clay and sand samples were obtained above the groundwater level where water is in tension and transported by thermal gradient during a year. The clay at the Clay Site and the sand at the Sand Site were tested for erodibility in November 2014 and June 2015. The samples had a range of field water content and field density. The erosion test was the Erosion Function Apparatus (EFA) test. The clay samples were tested undisturbed with field water content while the sand samples were reconstituted to their natural water content and density.

The erosion function for the clay samples and the sand samples were obtained. They gave the critical velocity as well as the complete erosion function. The possible relationships between the critical velocity and the soil properties were studied. It was found that the erodibility of clays is more complex and has more influencing factors than the erodibility of sand. Sometimes opposite trends are found between the two soil types. Much more data needs to be collected before stronger conclusions can be reached. This is the purpose of a new NCHRP project in which the authors are involved.

\section{Acknowledgements}

The authors wish to thank Fugro and especially Scott Marr for their help with drilling and sampling. The authors also wish to thank colleagues and graduate students at Texas A\&M University for their contributions to the laboratory and field work.

\section{References}

1. Briaud J.-L., Geotechnical Engineering: unsaturated and saturated soils, John Wiley and Sons, 1000 pp. (2013)

2. Briaud, J.-L. The National Geotechnical Experimentation Sites at Texas A\&M University: Clay and Sand; Data collected until 2002; Report NGES -TAMU-001, 311 p., Civil Engineering, Texas A\&M University, College Station, Texas, USA (2003)

3. Cao Y., Wang J. , Briaud J.L., Chen H.C., Li Y., Nurtjahyo P. "EFA Tests and the influence of Various Factors on the Erodibility of Cohesive Soils", Proceedings of the First International Conference on Scour of Foundations, Texas A\&M University, Dpt. of Civil Engineering, College Station, TX, USA (2002)

4. Croad, R.N. Physics of Erosion of Cohesive Soils, $\mathrm{PhD}$ Thesis, Department of Civil Engineering, University of Auckland, Auckland, New Zealand (1981)

5. Dashko, R.E., Shidlovskaya, A.V. Physical and Chemical Genesis of Swell and Osmotic Shrinkage of Clay Soils in Construction's Base by Results of Experimental Research". Notes of the University of Mines. St. Petersburg. Russia. V. 200, pages 4-14. (2012)

6. Dashko, R.E., Shidlovskaya, A.V. "Engineering Geological and Geotechnical Approach to Clay Soils 
of Different Genesis". Proceedings of the Eighth Russian Conference on the Engineering Survey for Construction. Moscow, Russia, organized by PNIIIS, 13-14 December 2012, published by Geomarketing, Pages 12-14. (2012)

7. Reddy, G.B. "An experimental investigation of subsurface ground temperature in Texas: a complete study", International Journal on Ambient Energy. Volume 21, Issue 4. (2000) 